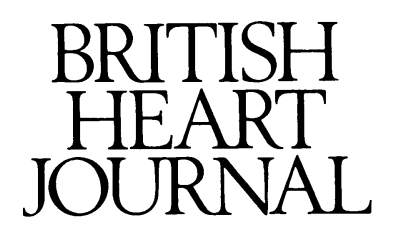

Editorial

\title{
The case for concomitant carotid and coronary artery surgery
}

There is continuing controversy about the best management for patients with severe coronary artery disease who also have important carotid disease. Approaches vary from totally ignoring carotid stenoses at the time of myocardial revascularisation, to performing staged operations, or combining the two operations during one anaesthesia.

Numerous studies have been published which when considered together establish a strong case for concomitant carotid endarterectomy and coronary bypass grafting being the safest and most long lasting approach in patients with coexistent severe carotid and coronary disease. To arrive at this conclusion, one must answer the questions facing any new technique, namely, "Does it work?" and "Is it necessary?" Therefore, one must establish that each surgical procedure is the appropriate treatment for patients with carotid or coronary disease, that each disease poses a risk during operations that address only one of the lesions, and that the combined operation yields the best results.

\section{Carotid endarterectomy for patients with symptomatic carotid stenoses}

In 1986 Hertzer and coworkers reported significant freedom from neurological events in symptomatic patients who had carotid endarterectomy rather than medical treatment. ${ }^{1}$ The North American Symptomatic Carotid Endarterectomy Trial confirmed significant freedom from any stroke, any ipsilateral stroke, and any stroke or death in patients who had endarterectomy rather than medical treatment. ${ }^{2}$ Similar results were reported from the European Carotid Surgery Trial. ${ }^{3}$

\section{Carotid endarterectomy for patients with asymptomatic carotid lesions}

Also in 1986 Hertzer and associates reported significant freedom from late neurological events in surgically treated patients when they were compared with medically treated patients with asymptomatic stenoses. ${ }^{4}$ In 1993 the Veterans Affairs Cooperative Study Group reported a significant reduction in the overall incidence of ipsilateral neurological events after carotid endarterectomy in patients with asymptomatic lesions. ${ }^{5}$ Lately, the National Institutes of Health abruptly ended a randomised trial of carotid endarterectomy versus medical treatment for asymptomatic carotid lesions because of the overwhelming advantages of surgery. ${ }^{6}$

\section{Coronary bypass grafting in patients with coronary artery disease}

Coronary bypass grafting has long-term advantages in terms of survival and symptom relief over medical treatment for most cohorts of patients with coronary artery disease. ${ }^{7}$ Additionally in all major studies comparing bypass grafting and percutaneous angioplasty, patients treated surgically had a significant advantage in terms of event-free survival. ${ }^{8-10}$

\section{The risks}

Does the presence of significant disease in one arterial system pose an important threat to patients with combined diseases if an operation is directed only at the other system?

The major contribution of coronary artery disease to the short-term risks of carotid endarterectomy has been well established. ${ }^{11}$ In addition Hertzer and coworkers found that the greatest long-term risk to all patients who have carotid endarterectomy is posed by the complications of coronary disease, especially myocardial infarction, the leading cause of death. ${ }^{12} 13$ In one of Hertzer's groups of 209 patients with clinically suspected coronary disease who had carotid endarterectomy and were followed up for 11 years, survival was much improved in patients who had bypass grafting rather than continued medical treatment. ${ }^{12}$

The Cleveland Clinic group also found a high incidence of coronary disease in carotid endarterectomy patients; only $7 \%$ of patients had normal coronary arteries on prospective coronary angiography. ${ }^{14}$ Clearly, coronary artery disease poses important short-term and long-term risks in patients with carotid stenosis.

Perioperative stroke after coronary grafting is an issue of increasing importance to cardiac surgeons, particularly as the age of bypass patients continues to rise and with it the risk of stroke. Gardner and associates reported a stroke rate of $0.2 \%$ for coronary bypass patients $<45$ years of age, which increased progressively to $8.0 \%$ for patients $>75$ years. $^{15}$ Tuman and colleagues noted a stroke rate of $0.9 \%$ for patients $<65$ years old compared with $8.9 \%$ for patients $>75$ years, with the frequency of stroke rising geometrically after age $65 .{ }^{16}$ To place the impact of this risk in perspective, in my coronary bypass practice at the Massachusetts General Hospital in 1993, the mean age of my patients was 67 years and $20 \%$ were $>75$ years old.

Because stroke is an important complication of coronary bypass grafting and its incidence is rising, we need 
to relate this risk of stroke to carotid disease. In 1988 Reed and coworkers from our hospital reported that the presence of carotid bruits increased the risk of stroke about fourfold after coronary bypass grafting. ${ }^{17}$ Before operation Faggioli et al non-invasively evaluated 539 coronary bypass patients with no symptoms of carotid ischaemia; $8 \cdot 7 \%$ had carotid stenosis $>75 \% .{ }^{18}$ The odds ratio for stroke after coronary grafting was 9.9 in the presence of $>75 \%$ carotid stenosis when compared with patients without significant carotid stenosis. Patients $>60$ years old with $>75 \%$ carotid stenosis had a stroke rate of $15 \%$ compared with $0.6 \%$ in patients of the same age with no carotid disease. Importantly in Faggioli's series, none the 19 patients with $>75 \%$ carotid stenosis who had prophylactic carotid endarterectomy combined with coronary grafting had a perioperative stroke compared with four $(14.3 \%)$ of the 28 patients with $>75 \%$ carotid stenosis who did not have endarterectomy.

\section{The combined operation}

If the presence of significant carotid stenosis increases the risk of stroke after myocardial revascularisation, and if coronary events are the most common complication after carotid endarterectomy, then both diseases need to be considered together when planning coronary grafting in patients with coexistent severe disease. Timing of carotid endarterectomy in relation to coronary grafting now becomes the important issue. In 1989 Hertzer and associates prospectively randomised 129 patients with unstable coronary disease with unilateral, asymptomatic carotid lesions to either combined carotid and coronary surgery (71 patients) or coronary grafting with delayed endarterectomy (58 patients). ${ }^{19}$ The risk of stroke was $2 \cdot 8 \%$ for the combined operations and $14.4 \%(6.9 \%$ at the time of coronary grafting and $7.5 \%$ at the time of delayed carotid endarterectomy) for the staged procedures $(P<0.05)$.

Because of growing evidence establishing the efficacy of concomitant carotid and coronary operations our surgical group has increasingly used this approach for patients with combined disease. Between October 1979 and December 1991 combined operations were performed on 167 consecutive patients $(74 \%$ male, mean age 66 years). Unstable angina pectoris was the presenting complaint in $68 \%$ of patients: $65 \%$ had triple vessel disease and $42 \%$ left main coronary stenosis. Either prior

1 Hertzer NR, Flanagan RA, O'Hara PJ, Beven EG. Surgical versus nonoperative treatment of symptomatic carotid stenosis. Ann Surg 1986, 204:154-62.

2 North American Symptomatic Carotid Endarterectomy Trial Collaborators. Beneficial effect of carotid endarterectomy in symptomatic patients with high-grade carotid stenosis. N Engl F Med 1991;325. 445-53.

3 European Carotid Surgery Trialists' Collaborative Group. MRC European Carotid Surgery Trial: Interim results for symptomatic patients with severe $(70-99 \%)$ or with mild $(0-29 \%)$ carotid stenosis. patients with severe (70-99\%
Lancet $1991 ; 337: 1235-43$.

4 Hertzer NR, Flanagan RA, O'Hara PJ, Beven EG. Surgical versus nonoperative treatment of asymptomatic carotid stenosis. Ann Surg 1986; 204:163-71.

5 Hobson RW, Weiss DG, Fields WS, et al. Efficacy of carotid endarterectomy for asymptomatic carotid stenosis. N Engl $\tilde{F}$ Med 1993;328:221-7.

6 Altman LK. The New York Times, October 1, 1994, page 1.

7 Kirklin JW, Akins CW, Blackstone EH, et al. Guidelines and indications for coronary artery bypass graft surgery. $\mathcal{F} \mathrm{Am}$ Coll Cardiol 1991;17: 543-89.

8 RITA Trial Participants. Coronary angioplasty versus coronary artery bypass surgery: the Randomized Intervention Treatment of Angina bypass surgery: the Randomized Int
(RITA) trial. Lancet 1993;341:573-80.

9 Hamm CW, Reimers J, Ischinger T, et al. A randomized study of coronary angioplasty compared with bypass surgery in patients with symptonary angioplasty compared with bypass surgery in patients with symp
matic multivessel coronary disease. $N$ Engl $\Im$ Med 1994;331:1037-43.

10 King SB, Lembo NJ, Weintraub WS, et al. A randomized trial comparing coronary angioplasty with coronary bypass surgery. $N$ Engl f Med 1994; 331:1044-50. stroke or transient ischaemic attacks were present in 71 patients (42\%): 96 (57\%) were neurologically symptom free. All patients had severe carotid disease-that is, residual lumen $<1.5 \mathrm{~mm}$ or stenosis $>70 \%$. Postoperative complications included death in six patients $(3.6 \%)$, myocardial infarction in three patients $(1.8 \%)$, and transient or permanent stroke in seven patients $(4 \cdot 2 \%)$. Eight year follow up showed freedom from new neurological events in $97 \%$.

\section{Implications}

Admittedly most of the evidence supporting the policy of combined operations is drawn from reports in which the severity of the patients' coronary disease made coronary bypass grafting the most appropriate treatment, and the carotid disease was identified incidentally. For patients with severe carotid stenosis but only moderate coronary disease, the proven benefits of carotid endarterectomy are probably best obtained with isolated endarterectomy performed under local anaesthesia or with careful intraoperative haemodynamic monitoring.

The main difficulty with a uniform policy of performing combined operations for coronary bypass patients with coexistent severe carotid disease is identifying those patients with significant carotid stenosis. Carotid bruits, along with a history of neurological symptoms or events, are appropriate indications for further non-invasive testing, but are themselves of limited usefulness in predicting the severity of stenosis. ${ }^{20}$ Whereas focal bruits become more common with increasing degrees of carotid stenosis (reaching a maximum in the $70 \%$ to $89 \%$ range) they become less common as the degree of stenosis exceeds $90 \%$. We are currently trying to define at what age routine non-invasive carotid testing becomes cost effective.

Also, though there is clear evidence of an important risk associated with carotid stenoses $>70 \%$, the risk associated with lesser degrees of stenosis is not well defined, and the benefits of prophylactic endarterectomy in such situations remain questionable. The presence of carotid plaque ulceration is known to increase the risk of stroke in patients with stenoses $>70 \%$, but as yet its impact on lesser degrees of stenosis is unknown. ${ }^{21}$

Cardiac Surgical Unit,

CARY W AKINS

Harvard Medical School,

Massachusetts General Hospital,

Boston MA 02114, USA

11 Ennix CL, Lawrie GM, Morris GC, et al. Improved results of carotid endarterectomy in patients with symptomatic coronary disease. An analysis of 1,546 consecutive carotid operations. Stroke 1979;10:122-5.

12 Hertzer NR, Lees CD. Fatal myocardial infarction following carotid endarterectomy. Ann Surg 1981;194:212-8.

13 Hertzer NR, Arison R. Cumulative stroke and survival ten years after carotid endarterectomy. $\mathcal{F}$ Vasc Surg 1985;2:661-8.

14 Hertzer NR, Young JR, Beven EG, et al. Coronary angiography in 506 patients with extracranial cerebrovascular disease. Arch Intern Med patients with extrac

15 Gardner TJ, Horneffer PJ, Manolio TA, Hoff SJ, Pearson TA. Major stroke after coronary artery bypass surgery: Changing magnitude of the stroke after coronary artery bypass surg
problem. $₹$ Vasc Surg 1986;3:684-7.

16 Tuman KJ, McCarthy RJ, Najafi H, Ivankovich AD. Differential effects of advanced age on neurologic and cardiac risks of coronary artery operations. ₹ Thorac Cardiovasc Surg 1992;104:1510-7.

17 Reed GL, Singer DE, Picard EH, DeSanctis RW. Stroke following coronary artery bypass surgery. $N$ Engl $₹$ Med 1988;319:1246-50.

18 Faggioli GL, Curl GR, Ricotta JJ. The role of carotid screening before coronary artery bypass. $\mathcal{f}$ Vasc Surg 1990;12:724-31.

19 Hertzer NR, Loop FD, Beven EG, O'Hara PJ, Krajewski LP. Surgical staging for simultaneous coronary and carotid disease: A study including prospective randomization. F Vasc Surg 1989;9:455-63.

20 Sauve JS, Thorpe KE, Sackett DL, et al. Can bruits distinguish highrade from moderate symptomatic carotid stenosis? Ann Intern Med 1994;120:633-7.

21 Eliasziw M, Streifler JY, Fox AJ, et al. Significance of plaque ulceration in symptomatic patients with high-grade carotid stenosis. Stroke 1994;25: 304-8. 